\title{
Quantifying the Effects of Fusarium Head Blight on Grain Yield and Test Weight in Soft Red Winter Wheat
}

\author{
Jorge David Salgado, Laurence V. Madden, and Pierce A. Paul
}

Department of Plant Pathology, The Ohio State University, Ohio Agricultural Research and Development Center, Wooster 44691. Accepted for publication 3 October 2014.

\begin{abstract}
Salgado, J. D., Madden, L. V., and Paul, P. A. 2015. Quantifying the effects of Fusarium head blight on grain yield and test weight in soft red winter wheat. Phytopathology 105:295-306.

Fusarium head blight (FHB), caused by the fungus Fusarium graminearum, is known to negatively affect wheat grain yield (YLD) and test weight (TW). However, very little emphasis has been placed on formally quantifying FHB-YLD and FHB-TW relationships. Field plots of three soft red winter wheat cultivars-'Cooper' (susceptible to FHB), 'Hopewell' (susceptible), and 'Truman' (moderately resistant)-were grown during the 2009, 2010, 2011, and 2012 seasons, and spray inoculated with spore suspensions of $F$. graminearum and Parastagonospora nodorum to generate a range of FHB and Stagonospora leaf blotch (SLB) levels. FHB index (IND) and SLB were quantified as percent diseased spike and flag leaf area, respectively, and YLD $\left(\mathrm{kg} \mathrm{ha}^{-1}\right)$ and TW $\left(\mathrm{kg} \mathrm{m}^{-3}\right)$ data were collected. Using IND as a continuous covariate and cultivar (CV) and SLB as categorical fixed effects, linear mixed-model regression analyses (LMMR) were used to model the IND-YLD and IND-TW relationship and to determine whether these relationships were influenced by CV and SLB. The final models fitted to the data were of the

generic form $y=a+b(I N D)$, where $a$ (intercept) or $b$ (slope) could also depend on other factors. LMMR analyses were also used to estimate $a$ and $b$ by combining the studies from these 4 years with an additional 16 experiments conducted from 2003 to 2013, and bivariate random-effects meta-analysis was used to estimate population mean $b(\bar{b})$ and $a(\bar{a})$ for the IND-YLD relationship. YLD and TW decreased as IND increased, with $b$ ranging from -3.2 to $-2.3 \mathrm{~kg} \mathrm{~m}^{-3} \%^{-1}$ for TW. For the IND-YLD relationship, $\bar{b}$ was $-51.7 \mathrm{~kg} \mathrm{ha}^{-1} \% \mathrm{IND}^{-1}$ and $\bar{a}$ was $4,426.7 \mathrm{~kg} \mathrm{ha}^{-1}$. Neither cultivar nor SLB affected the IND-YLD relationship but SLB affected $a$ of the IND-TW regression lines, whereas cultivar affected $b$. Plots with the highest levels of SLB (based on ordinal categories for SLB) had the lowest $a$ and Hopewell had the highest $b$. The level of IND at which a $50-\mathrm{kg} \mathrm{m}^{-3}$ reduction in TW was predicted to occur was 19,16 , and $22 \%$ for Cooper, Hopewell, and Truman, respectively. A yield loss of $1 \mathrm{MT} \mathrm{ha}^{-1}$ was predicted to occur at $19 \%$ IND. The rate of reduction in relative TW or YLD per unit increase in IND was between -0.39 and $-0.32 \%^{-1}$ for TW and $-1.17 \%^{-1}$ for YLD. Results from this study could be integrated into more general models to evaluate the economics of FHB management strategies.
\end{abstract}

Fusarium head blight (FHB) or head scab, caused predominantly by Fusarium graminearum in North America, is a disease of economic importance in wheat (Triticum aestivum L.) in Ohio and other parts of the world $(8,25,26,30)$. Under favorable conditions (wet, humid weather during anthesis and early grainfill), FHB may significantly reduce grain yield and test weight. In addition, FHB-affected grain may become contaminated with deoxynivalenol (DON), a mycotoxin produced by $F$. graminearum, which represents a health threat to humans and livestock $(29,37)$. Consequently, grain contaminated with DON above $2 \mathrm{ppm}$ (threshold established by the United States Food and Drug Administration) may be rejected or priced down by grain buyers $(25,26)$. Further price discounts are usually applied to grain lots with Fusarium-damaged kernels (FDK) above and test weight below established thresholds $(26,40,41)$.

Management strategies to minimize losses due to FHB include cultural practices, cultivar resistance, and the application of foliar fungicides (49). However, there are costs associated with the use of each of these strategies. Many of the moderately resistant soft red winter wheat cultivars have low-to-moderate yield potential when compared with some of the susceptible cultivars. Consequently, producers may earn less as a result of lower grain yield if a resistant cultivar is planted in a low-disease year (40). Similarly, because fungicides are not $100 \%$ effective against FHB $(11,33$, 49 ), producers may incur the costs associated with spraying their

Corresponding author: P. A. Paul; E-mail address: paul.661@ @osu.edu

http://dx.doi.org/10.1094/PHYTO-08-14-0215-R

(c) 2015 The American Phytopathological Society fields without seeing the benefits in terms of disease and toxin reduction and grain yield and quality increase. However, in a year with moderate levels of disease, the $70 \%$ reduction in FHB and DON accomplished through the integration of resistance and fungicide (49) may be sufficient to minimize losses and reduce price discounts. Given the year-to-year viability in FHB and the fact that no management approach is $100 \%$ effective against this disease, further research is needed to understand the cost-benefit of using integrated management strategies, taking other wheat production issues into consideration.

There is clearly a need for models to evaluate the economics of FHB management strategies to help producers make more informed management decisions. However, the development of such models requires knowledge, understanding, and quantitative estimates of losses caused by this disease, as well as quantitative estimates of the effects of different management strategies on FHB, DON, grain yield, test weight, and their relationships. Some work has been done to characterize and quantify some of these effects in detail $(6,27,33,34,36,38,40,47,49)$ but less emphasis has been placed on quantifying the FHB-yield and FHB-test weight relationships. There are numerous reports of yield loss due to FHB in the literature but, in most cases, specific quantitative information pertaining to the FHB-yield relationship is not provided (30). One notable exception is the work done by Snijder (44), in which regression models describing the FHB-yield relationship were developed; however, these models were based on data collected from wheat plots inoculated with F. culmorum, an FHB-causing species that is not predominant in North America. 
Madden and Paul (23) used data from U.S. uniform fungicide trials (UFTs) to developed a linear model for yield $(y)$ in relation to FHB index (IND) of the form $y=a+b$ (IND), where $a$ (intercept) is the FHB-free yield (dependent on all factors other than FHB) and $b$ (slope) is the decline in $y$ per unit increase in FHB. Estimates of $a$ depended on wheat class but estimates of $b$ did not. Although this work demonstrates that yield can be related functionally to FHB, further investigation is needed to evaluate other aspects of this relationship. The UFT-results were based on generally susceptible cultivars but the functional response ( $a$ and especially $b$ ) could depend on cultivar resistance or other cultivar traits as well as the severity of other diseases. Thus, yield-loss results from the UFTs are best considered the first stage in developing models for yield (or test weight) in relation to FHB.

Foliar diseases of wheat such as Stagonospora leaf blotch (SLB), caused by Parastagonospora nodorum (Berk.) Quaedvl., Verkley \& Crous) (39), formerly classified as Stagonospora nodorum Berk (teleomorph: Phaeosphaeria nodorum (E. Müll.) Hedjar.), are very common during the spring and early summer in wheat fields in Ohio, the Midwest, and other wheat-producing regions of the world (5,12-14). F. graminearum and $P$. nodorum are both residue borne and both diseases are driven by rainfall and high relative humidity $(18,28,42,45)$. In addition, they both have similar effects on grain yield and quality. Therefore, it is quite possible that the relationship between FHB and yield is influence by SLB. Moreover, because both diseases are managed using a similar set of strategies (crop rotation, tillage, and fungicides), efforts to minimize yield and quality losses caused by one likely will also minimize losses caused by the other.

The objective of this study was to evaluate and develop statistical models for the effects of cultivar and SLB severity on the IND-yield and IND-test weight relationships. Linear mixedmodel regression analyses were used to relate test weight to IND and yield to IND, as influenced by cultivar and SLB, and metaanalysis was then used to combine intercepts and slopes for the IND-yield relationship from multiple studies. Derived empirical models will serve as the basis for economic analysis of FHB management strategies in future studies.

\section{MATERIALS AND METHODS}

Plot establishment and design of the experiment. Field experiments were conducted during the 2009, 2010, 2011, and 2012 wheat-growing seasons at the Ohio Agricultural Research and Development Center near Wooster. Plots of three soft red winter wheat cultivars ('Truman': moderately resistant to FHB, moderate yield potential and late-maturing; 'Hopewell': susceptible to FHB, moderate-high yield potential and midseason; and 'Cooper': susceptible to FHB, moderate-high yield potential and earlymaturing) were planted in fields previously cultivated with oat or soybean on 25 September 2008, 7 October 2009, 8 October 2010, and 7 October 2011. All plots were planted using a Kincaid wheat drill at a seeding rate of $4 \times 10^{6}$ seeds/ha, and managed according to standard agronomics practices for Ohio (4).

The experiment was designed as a split-split-plot, with cultivar as whole plot (three levels), P. nodorum inoculation treatment as subplot (three levels), and $F$. graminearum inoculation treatment as sub-subplot (nine levels) in three replicate blocks. In each block, each $243-\mathrm{m}^{2}$ (useful area, not including the alleyways) whole plot of each cultivar was divided into three $81-\mathrm{m}^{2}$ subplots to which $P$. nodorum inoculation treatments were randomly assigned. Then, each subplot was divided into nine sub-subplots of 1.5 by $6 \mathrm{~m}$ to which $F$. graminearum inoculation treatments were randomly assigned. In 2010 , sub-subplots were 1.5 by $3 \mathrm{~m}$. Each subsubplot consisted of 7 rows, with a 19-cm spacing between rows. There were alleyways 0.6 to $1.5 \mathrm{~m}$ wide between adjacent plots.

Inoculation and data collection. Inoculations were done to obtain different levels of disease and a wide range of disease intensity for both SLB and FHB affecting grain yield and quality. Therefore, the effect of specific inoculum densities per se for either of these two diseases was not the main focus of this study. Inoculum was prepared and plots were inoculated as previously described $(12,13,40,41)$. In brief, the final macroconidia, ascospore, and pycnidiospore concentration was determined using a hemocytometer (Reichert-Bright Line; Hausser Scientific, Horsham, PA), and adjusted to the final concentrations by adding deionized water mixed with Tween 20 (2\%). Subplot and sub-subplot treatments were assigned by spray inoculating plots with pycnidiospore suspensions of $P$. nodorum and a 1:1 mixture of macroconidia and ascospores of $F$. graminearum, respectively, at concentrations of 0 , 0.25 , and $0.5 \times 10^{6}$ spores $\mathrm{ml}^{-1}$ in $2009 ; 0,0.5$, and $1 \times 10^{6}$ spores $\mathrm{ml}^{-1}$ in 2010 and 2011; and 0,1 , and $2 \times 10^{6}$ spores $\mathrm{ml}^{-1}$ in 2012, for the first pathogen; and $0,1,3,5,7,9,11,13$, and $15 \times 10^{4}$ spores/ $\mathrm{ml}$ for the second $(0,30,60,90,120,150,180,210$, and $240 \times$ $10^{3}$ spores $/ \mathrm{ml}$ in 2012). Inoculations were done at full flag leaf emergence (Feekes GS 9) for P. nodorum and at anthesis (Feekes 10.5.1) for $F$. graminearum. Plots reached full flag leaf emergence during the first, second, third, and first week of May 2009, 2010, 2011, and 2012, respectively; and anthesis during the last week of May 2009, 2010, and 2011 and the third week of May 2012.

SLB severity (percent diseased leaf area) was rated on the flag leaf of 6 to 10 arbitrarily selected clusters of 3 to 5 tillers per subsubplot at the milky ripe growth stage (Feekes 11.1) (14). Six clusters were rated in 2010, the years in which the sub-subplots were smaller, and 10 in the other 2 years, when plots were larger. Ratings were done during the first (2012) or second (2010 and 2011) week of June. Due to time constraints, SLB severity was not rated as a percentage in 2009. Plots were only visually inspected and scored on an ordinal scale (low, moderate, and high) during the second week of June. IND (mean proportion of diseased spikelets per spike) $(32,46)$ was evaluated at soft dough (Feekes GS 11.2) on 50 to 100 spikes (five groups of 10 to 20 spikes) sampled at multiple arbitrarily selected sites within each sub-subplot. FHB ratings were done during the second (2012) or third (2009 to 2011) week of June.

Wheat plots were harvested on 10, 9, and 20 July 2009, 2010, and 2011, respectively, and on 26 June 2012, when grain moisture was approximately $13 \%$. All plots were harvested using an ALMACO SPC20 (ALMACO, Nevada, IA) research plot combine harvester and grain yield (bushels per acre), test weight (pounds per bushel), and moisture were determined directly on the combine using an electronic grain gage (HarvestMaster HM1000 GrainGage; Juniper Systems, Inc., Logan, UT), coupled with a field computer (Allegro MX Field PC; Juniper Systems, Inc., Logan, UT). Yield was then adjusted to $13.5 \%$ moisture and converted to kilograms per hectare based on a bushel weight of $27 \mathrm{~kg} /$ bushel. Test weight was converted to kilograms per cubic meter.

Data analysis. Mixed-model regression analysis. Relationships between IND and test weight and IND and grain yield were modeled by treating IND as a continuous covariate and cultivar and SLB severity classes (based on $P$. nodorum inoculation treatment) as indicator variables in the analyses. SLB severity was treated as a categorical variable because it was scored on an ordinal scale (low, moderate, and high) in one of the 4 years of this study. Preliminary analysis of the effects of $P$. nodorum inoculation treatment on SLB severity showed that inoculated plots generally had significantly higher mean SLB severity than noninoculated plots (data not shown), and plots inoculated with the high $P$. nodorum spore concentration had numerically but not always statistically higher mean SLB than plots inoculated with the low concentration. Therefore, these results were used as the basis and justification for our decision to use none, low, and high $P$. nodorum inoculum levels to represent low, moderate, and high SLB severity classes, respectively. Each experiment (each year) was first analyzed separately using PROC GLIMMIX of SAS (SAS Institute, Cary, NC) (20); then, based on results from the 
initial analyses, data were pooled for subsequent analyses. Year, block, and all interactions involving year and block were treated as random effects, whereas IND, cultivar, and SLB severity class were treated as fixed effects. Fixed effects were evaluated with $F$ tests and random effects with standard normal test statistics (Table 1). Details of the mixed-model regression analysis are in the appendix.

Meta-analysis of IND-yield relationship. Result from the regression analysis of the data showed that SLB did not affect the IND-yield relationship in any of the years of this study (see Results and Table 1). Therefore, after removing SLB severity class and other nonsignificant terms, the final model fitted to the yield data for each years was of the form $y_{i}=a_{i}+b$ (IND), where $a_{i}$ represents a separate intercept for each cultivar and $b$ a common slope (nonsignificant cultivar $\times$ IND interaction) $(P>0.05)$. The estimated intercepts and slopes and their standard errors for each cultivar-year combination were then combined with corre- sponding parameters and statistics from 16 additional experiments conducted in Ohio from 2003 to 2013 using one or more of the same three cultivars (Cooper, Hopewell, and Truman), and metaanalysis was used to estimate the overall mean intercept and slope $(24,34,35)$.

The experimental design, inoculation, and data collection protocols used in the 16 experiments (Table 2) were similar to those described above. For instance, in 14 of the 16 experiments, the experimental design was a randomized complete block with a split-plot arrangement of treatment factors. Different planting dates, $F$. graminearum inoculum densities (as described above), inoculation timings (early, mid-, or late anthesis), levels of infield corn residue $(0,15$, and $80 \%$ ground cover), fungicide treatments (products or application timing), or a combination of two or more of these factors were used to generate a range of index levels and corresponding grain yields. For the other two experiments, the design was a randomized complete block, with

TABLE 1. Probability values (significance levels: $P$ ) from linear mixed-model regression analyses to determine the effects of cultivar (CV), Stagonospora leaf blotch severity classes (SLB), and Fusarium head blight index (IND; as a continuous covariate) on grain yield and test weight for each of 4 years ${ }^{\mathrm{a}}$

\begin{tabular}{|c|c|c|c|c|c|c|c|c|}
\hline \multirow[b]{2}{*}{ Factors ${ }^{b}$} & \multicolumn{4}{|c|}{ Grain yield } & \multicolumn{4}{|c|}{ Test weight } \\
\hline & 2009 & 2010 & 2011 & 2012 & 2009 & 2010 & 2011 & 2012 \\
\hline $\mathrm{CV}$ & $<0.001$ & 0.448 & 0.710 & 0.521 & 0.755 & 0.019 & 0.892 & 0.223 \\
\hline SLB & 0.930 & 0.110 & 0.996 & 0.558 & 0.475 & 0.089 & 0.791 & 0.281 \\
\hline IND & $<0.001$ & $<0.001$ & 0.371 & 0.978 & $<0.001$ & $<0.001$ & 0.291 & 0.206 \\
\hline $\mathrm{IND} \times \mathrm{CV}$ & 0.233 & 0.227 & 0.644 & 0.651 & 0.032 & 0.764 & 0.363 & 0.371 \\
\hline IND $\times$ SLB & 0.720 & 0.517 & 0.843 & 0.645 & 0.718 & 0.282 & 0.757 & 0.235 \\
\hline
\end{tabular}

a Grain yield $\left(\mathrm{kg} \mathrm{ha}^{-1}\right)$ and test weight $=$ grain weight per unit volume $\left(\mathrm{kg} \mathrm{m}^{-3}\right)$.

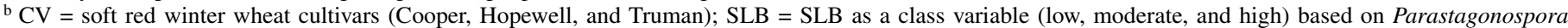
nodorum inoculum densities (none, low, and high $=0,0.25$, and $0.5 \times 10^{6}$ in 2009; 0 , 0.5 , and $1 \times 10^{6}$ spores $/ \mathrm{ml}$ in 2010 and 2011 ; and 0 , 1 , and $2 \times 10^{6}$ spores/ml in 2012); IND = FHB index (mean proportion of diseased spikelets per spike) as a continuous covariate.

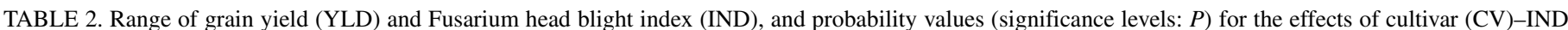

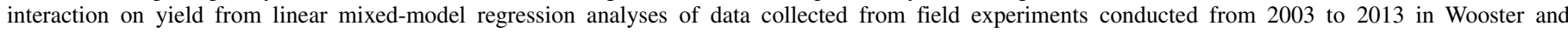
Hoyteville, $\mathrm{OH}$

\begin{tabular}{|c|c|c|c|c|c|c|c|c|}
\hline \multirow[b]{2}{*}{ Experiment } & \multirow[b]{2}{*}{ Location, year } & \multirow[b]{2}{*}{ Factors $^{\mathrm{a}}$} & \multirow[b]{2}{*}{$\mathrm{CV}$} & \multicolumn{2}{|c|}{ Range $^{\mathrm{b}}$} & \multirow[b]{2}{*}{$N^{\mathrm{c}}$} & \multirow[b]{2}{*}{$P$ value $^{\mathrm{d}}$} & \multirow[b]{2}{*}{ Reference } \\
\hline & & & & YLD & IND & & & \\
\hline EPI03 & Wooster 2003 & RES, PD, CV & $\mathrm{H}$ & $1.1-4.9$ & $12-63$ & 54 & 0.023 & Paul et al. (31) \\
\hline EPI04 & Wooster 2004 & RES, PD, CV & $\mathrm{H}$ & $2.4-5.8$ & $0.2-16$ & 54 & 0.188 & Unpublished \\
\hline IPM05 & Wooster 2005 & RES, FUN, CV & $\mathrm{H}, \mathrm{T}$ & $3.9-6.4$ & $0-2.5$ & 36 & 0.504 & Unpublished \\
\hline IPM06 & Wooster 2006 & RES, FUN, CV & $\mathrm{H}, \mathrm{T}$ & $3.6-5.8$ & $0-8.3$ & 36 & 0.606 & Unpublished \\
\hline EPI107 & Wooster 2007 & $\mathrm{PD}, \mathrm{CV}, \mathrm{FG}$ & $\mathrm{H}, \mathrm{T}, \mathrm{C}$ & $1.3-5.5$ & $0-76$ & 54 & 0.745 & Li 2010 (19) \\
\hline EPI207 & Wooster 2007 & $\mathrm{PD}, \mathrm{CV}, \mathrm{FG}$ & $\mathrm{H}, \mathrm{T}, \mathrm{C}$ & $1.0-4.8$ & $0-69$ & 54 & 0.745 & Li 2010 (19) \\
\hline IPM08 & Hoyteville 2008 & CV, FUN & $\mathrm{H}, \mathrm{T}, \mathrm{C}$ & $3.8-5.2$ & $0.2-16$ & 52 & 0.675 & Li 2010 (19) \\
\hline IPM09 & Wooster 2009 & CV, FUN & $\mathrm{H}, \mathrm{T}, \mathrm{C}$ & $2.8-6.1$ & $1-18$ & 54 & 0.520 & Li 2010 (19) \\
\hline YL09 & Wooster 2009 & $\mathrm{CV}, \mathrm{FG}, \mathrm{STAG}$ & $\mathrm{H}, \mathrm{T}, \mathrm{C}$ & $3.5-6.7$ & $0-53$ & 243 & 0.293 & Unpublished \\
\hline YL10 & Wooster 2010 & CV, FG, STAG & $\mathrm{H}, \mathrm{T}, \mathrm{C}$ & $2.5-4.4$ & $1.7-41$ & 243 & 0.219 & Unpublished \\
\hline IPM10 & Wooster 2010 & CV, FUN & $\mathrm{H}, \mathrm{T}, \mathrm{C}$ & $3.3-5.1$ & $0.1-12$ & 72 & 0.933 & Willyerd et al. (49) \\
\hline DDA11 & Wooster 2011 & FUN & $\mathrm{H}$ & $2.6-4.9$ & $0.3-18$ & 40 & $\ldots$ & D'Angelo (9) \\
\hline IPM11 & Wooster 2011 & $\mathrm{CV}, \mathrm{FG}, \mathrm{FUN}$ & $\mathrm{H}, \mathrm{T}, \mathrm{C}$ & $2.0-6.1$ & $0.1-17$ & 160 & 0.867 & Salgado et al. (40) \\
\hline TIM11 & Wooster 2011 & CV, TIME, FG & $\mathrm{H}$ & $2.8-5.8$ & $0.2-17$ & 120 & 0.866 & D'Angelo et al. (10) \\
\hline YL11 & Wooster 2011 & CV, FG, STAG & $\mathrm{H}, \mathrm{T}, \mathrm{C}$ & $1.2-4.5$ & $0.7-19$ & 243 & 0.656 & Unpublished \\
\hline IPM12 & Wooster 2012 & CV, FG, FUN & $\mathrm{H}, \mathrm{T}, \mathrm{C}$ & $5.0-6.8$ & $0-14$ & 144 & 0.726 & Unpublished \\
\hline YL12 & Wooster 2012 & CV, FG, STAG & $\mathrm{H}, \mathrm{T}, \mathrm{C}$ & $2.6-5.4$ & $0-19$ & 243 & 0.653 & Unpublished \\
\hline DDA13 & Wooster 2013 & FUN & $\mathrm{H}$ & $3.7-5.5$ & $0.2-5$ & 40 & $\ldots$ & D’Angelo (9) \\
\hline TIM13 & Wooster 2013 & FG, FUN, TIME & $\mathrm{H}$ & $3.2-5.6$ & $0.1-8$ & 40 & $\ldots$ & D'Angelo et al. (10) \\
\hline IPM13 & Wooster 2013 & $\mathrm{CV}, \mathrm{FG}, \mathrm{FUN}$ & $\mathrm{H}, \mathrm{T}$ & $2.4-5.2$ & $0-18$ & 96 & 0.005 & Salgado et al. (40) \\
\hline
\end{tabular}

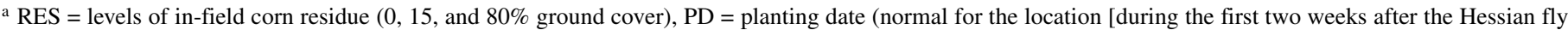
safe date] and late [7 to 10 days after]), $\mathrm{CV}=$ cultivar (one or more of up to six soft red winter wheat cultivars, including Cooper [C], Hopewell [H], and Truman $[\mathrm{T}]$ ), FUN = fungicide treatment (with and without one or more of the fungicides Prosaro, Folicur, Headline, or Quadris) applied at label-recommended rates before or at $50 \%$ anthesis, FG = Fusarium graminearum inoculation treatment (either different inoculum densities spray-applied at anthesis or the same density applied at different growth stages), STAG = Parastagonospora nodorum inoculation treatment (Materials and Methods), and TIME = fungicide application timing (anthesis and postanthesis applications of Prosaro or Caramba).

b Minimum and maximum YLD $\left(\mathrm{kg} \mathrm{ha}^{-1}\right)$ and IND (mean percentage of disease spikelets per spike).

${ }^{\mathrm{c}} N=$ total number of experimental units in each experiment.

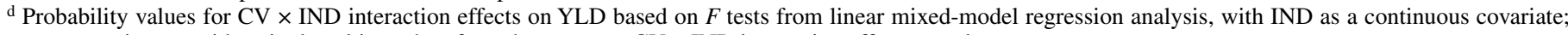
$\ldots=$ experiments with a single cultivar; therefore, there was no $\mathrm{CV} \times \mathrm{IND}$ interaction effect to evaluate. 
F. graminearum-spray-inoculated plots (as described above) of Hopewell subjected to 10 different fungicide treatments (Prosaro, Headline, and Quadris applied at three growth stages, plus an untreated check) (9), generating a range of IND and yield values. Plot dimensions, planting density, row spacing, data collection, and cropping practices were as described above. Fifteen of the experiments were conducted in Wooster and one in Hoyteville.

For each experiment, a mixed-model regression analysis was performed in PROC MIXED or GLIMMIX as described above (and in the Appendix), and intercepts and slopes were estimated for each cultivar. There were 45 unique sets of intercepts, slopes, and corresponding standard errors, representing different cultivarexperiment combinations. These were treated as separate studies in the meta-analysis. Using each pair of estimated intercept and slope from each individual study as the effect sizes, bivariate random-effects meta-analytical models were fitted in PROC MIXED of SAS (20) to estimate overall population mean intercept $(\bar{a})$ and slope $(\bar{b})$, using restricted maximum likelihood as the parameter estimation method. Readers can refer to Paul et al. (34), Paul and Madden (35), and Madden and Paul (24) for more details. The bivariate meta-analytical model can be written as

$$
\left(\begin{array}{l}
a \\
b
\end{array}\right)_{i} \sim N\left(\boldsymbol{\mu}, \boldsymbol{\Sigma}+\mathbf{C}_{i}\right)
$$

where $\sim N(\bullet$ indicates a (bivariate) normal distribution, $\boldsymbol{\mu}$ is the vector of effect sizes (unknown intercept and slope), and $\boldsymbol{\Sigma}$ and $\boldsymbol{C}_{i}$ are matrices of between- and within-study variances and covariances of the intercept and slope, respectively. The $\boldsymbol{C}_{i}$ matrix was determined from each individual study (using the $\operatorname{covb}$ option in the model statement of PROC MIXED when fitting a linear model to the data from each individual study), while $\boldsymbol{\mu}$ and $\boldsymbol{\Sigma}$ were estimated from the random-effects meta-analysis of the vector of intercept and slope across all of the studies. The $\boldsymbol{C}_{i}$ matrices were held fixed in the meta-analysis using a bivariate generalization of the data = option in MIXED, described in the Supplemental file of Madden and Paul (24). Significance of the effect sizes was determined with a standard normal test, and standard errors and 95\% confidence intervals of $\bar{a}$ and $\bar{b}$ were determined as described by Paul et al. (34). The models were subsequently refitted with cultivar as a categorical moderator variable and fixed effect, and the estimate statement in PROC MIXED was used to estimate mean effect sizes (slopes and intercepts), standard errors, and 95\% confidence intervals for each cultivar as described (34).

\section{RESULTS}

SLB and FHB. Cool weather in 2011 and dry conditions in 2012 resulted in relatively lower levels of SLB and FHB and narrower ranges of mean disease intensities compared with 2009 and 2010 (Fig. 1). SLB severity generally increased as inoculum density increased and varied among cultivars in each year. Higher levels of mean severity were observed in 2010 (10.7 to $40.8 \%$ ) compared with 2011 (2.8 to $13.2 \%$ ) and 2012 (1.1 to $17.3 \%$ ). Averaged across years and FHB inoculation treatments, higher mean SLB severity was observed for Cooper (6.2 to 16.7\%) and Hopewell (15.2 to 22.5\%) than for Truman (6.2 to 9.9\%) (Fig. 1A, C, and E). In 2009, plots were only visually inspected for SLB at and after anthesis. Trends in terms of differences in severity among inoculation treatments were similar to those observed in subsequent years.

For FHB, higher levels of disease were observed in both 2009 and 2010 compared with 2011 and 2012 (Fig. 1B, D, F, and G). In all years, except for 2011, mean IND increased as inoculum density increased, with the susceptible cultivars generally having higher mean disease than the moderately resistant cultivar at all inoculum densities (Fig. 1B, D, F, and G). The narrowest ranges of IND (difference between the highest and lowest mean IND) were observed in 2011 (2.37\% for Cooper, 3.15\% for Hopewell, and $1.15 \%$ for Truman).

Based on results from linear mixed-model analyses of the arcsine-transformed SLB data, the main and interaction effects of cultivar and inoculation treatments were statistically significant (data not shown). Similarly, for arcsine-transformed IND, the main and interaction effects of cultivar and inoculation treatment were statistically significant $(P<0.05$, ) in all years, except 2011 (data not shown). This suggested that, as indicated by the arithmetic mean in Figure 1F, the $F$. graminearum inoculations did not work in 2011.

Relationship between FHB and test weight and grain yield. Cultivar, SLB, and IND effects on test weight and yield. Mean grain yield and test weight varied among years and cultivars, being higher in 2009 than in the other 3 years (Fig. 2). Averaged across inoculation treatments, Cooper (the early-maturing cultivar with moderate to high yield potential) and Truman (the late-maturing cultivar with moderate yield potential) had the highest mean grain yield and the highest mean test weight, respectively, in 3 of the 4 years (Fig. 2). Conversely, Hopewell (the midseason maturing and moderate to high yielding cultivar) had the lowest mean grain yield in 3 of the 4 years (Fig. 2). The trend in terms of the difference in mean grain yield among the cultivars was similar for the pooled data from 20 experiments conducted over a period of 11 years (Fig. 2I).

When each year was analyzed separately, cultivar, SLB severity class, IND (as a covariate), and their interactions did not have significant effects on test weight or yield in 2011 and 2012 (years with the lowest levels of IND and SLB severity) (Table 1). The nonsignificant IND effect could be attributed to unsuccessful $F$. graminearum inoculations in 2011 and to the relatively narrow range of mean disease in 2012. However, results from 2009 and 2010 (years with the highest levels and widest ranges of FHB) showed that IND had a significant effect on both responses in both years. In addition, cultivar significantly affected yield, and cultivar $\times$ IND significantly affected test weight in 2009, whereas cultivar, cultivar $\times$ SLB severity class, and the three-way interaction significantly affected test weight in $2010(P<0.05)$ (Table 1$)$.

Modeling the IND-test weight relationship. Because the inoculations were not effective in 2011 and the range of mean IND was very narrow in 2012 (Fig. 1 and preliminary analyses of the raw data), these 2 years were removed from all analyses related to the IND-test weight relationship. One cannot model relationships between IND and test weight without a range of values for both variables or without IND values above some minimum level needed to impact test weight. Data from the 2009 and 2010 seasons were pooled and the regression analyses were repeated, with sequential removal of nonsignificant terms from the model. The final model fitted to the test weight data was of the form $y_{i j}=a_{j}+b_{i}$ (IND), where $a_{j}$ represents a separate intercept for each SLB level (i.e., a significant SLB severity class effect: $P=0.002$ ) and $b_{i}$ a separate slope for each cultivar (i.e., a significant cultivar $\times$ IND interaction $)(P<0.001)$. As indicated by the negative slopes in Table 3 , test weight decreased as IND increased. The rate of test weight decrease per unit increase in IND (\% scale) ranged from -3.2 to $-2.3 \mathrm{~kg} \mathrm{~m}^{-3} \%$, with Hopewell suffering the greatest reduction, followed by Cooper and Truman (Table 3; Fig. 3A to C). The height (the intercept) of the IND-test weight regression line was significantly affected by SLB severity class (based on the ordinal category of $P$. nodorum inoculum density). The plots with the lowest level of SLB (non-P. nodoruminoculated treatment) had significantly higher intercept (test weight at a given level of IND) than plots with moderate and high levels of SLB (the inoculated treatments; $P=0.021$ and 0.007 ). The difference between the intercepts of the IND-test weight regression lines for the moderate and high SLB severity classes $\left(2.33 \mathrm{~kg} \mathrm{~m}^{-3}\right)$ was not statistically significant $(P=0.661)$. 

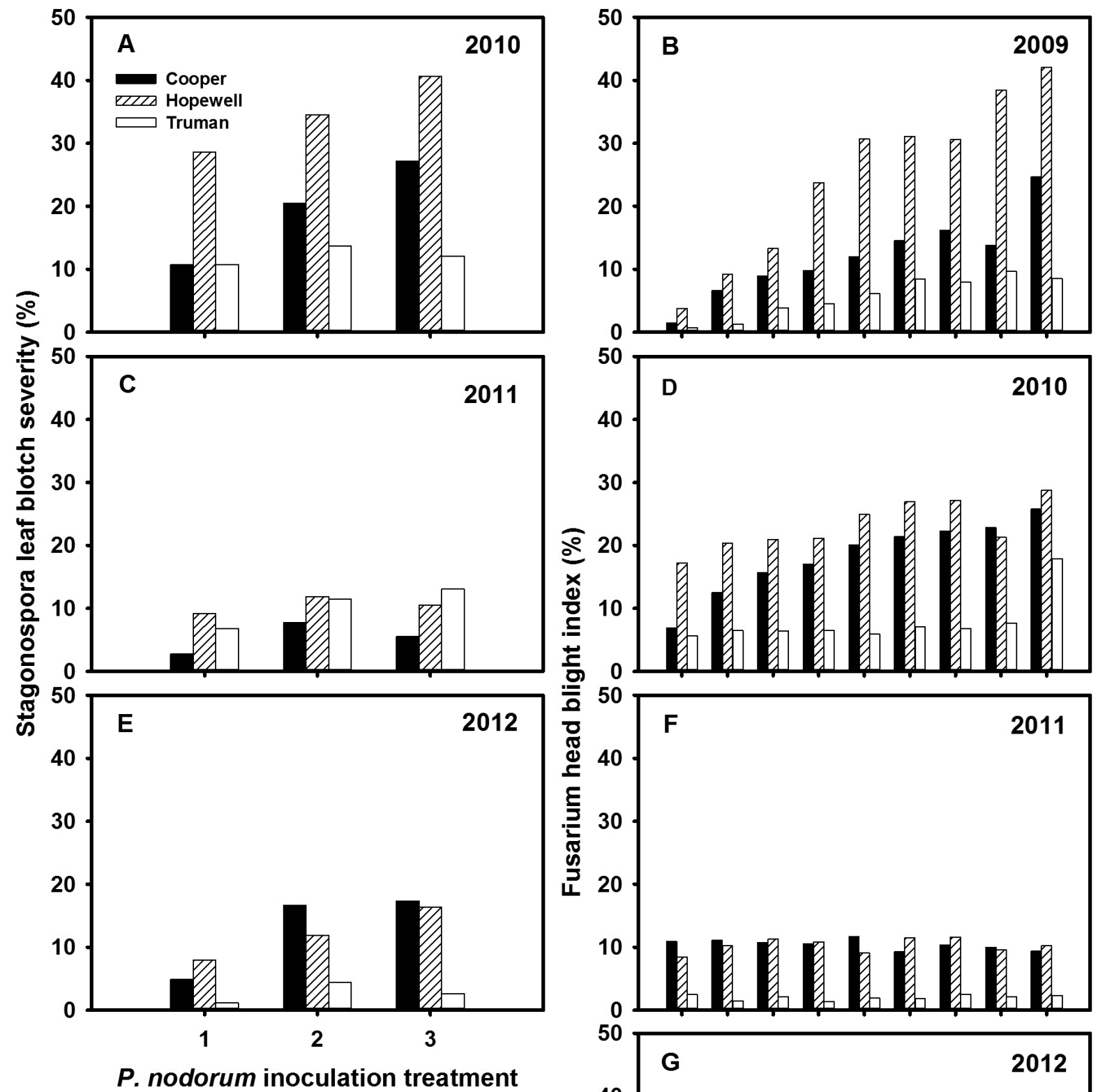

P. nodorum inoculation treatment

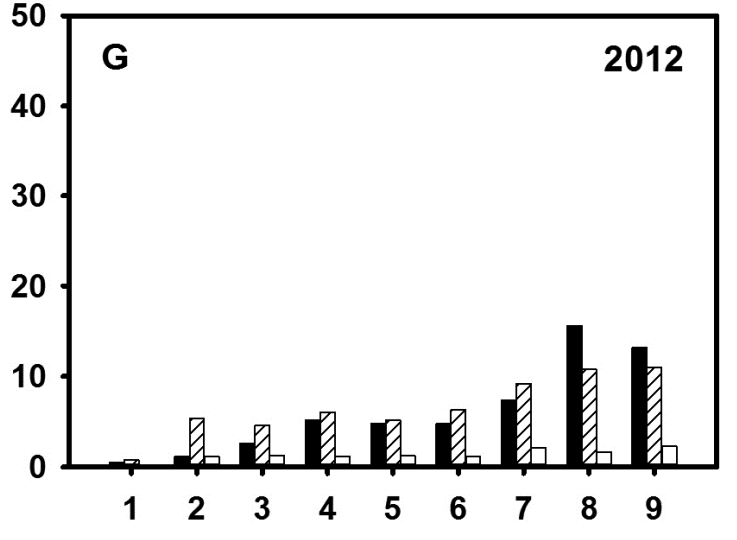

F. graminearium inoculation treatment

Fig. 1. A, C, and E, Mean Stagonospora leaf blotch (SLB) severity and B, D, F, and G, Fusarium head blight (FHB) index for plots of three soft red winter wheat cultivars (Cooper [susceptible to both SLB and FHB], Hopewell [susceptible to both SLB and FHB], and Truman [moderately resistant to both FHB and SLB]) inoculated with three $\left(1=\right.$ none, $2=$ low, and $3=$ high) Parastagonospora nodorum inoculum densities $\left(0,0.5\right.$, and $1 \times 10^{6} \mathrm{spores} / \mathrm{ml}$ in 2010 and 2011 and 0,1 , and $2 \times 10^{6}$ spores $/ \mathrm{ml}$ in 2012) at full flag leaf emergence (Feekes growth stage 9) and nine Fusarium graminearum inoculum densities (0, 1, 3, 5, 7, 9, 11, 13, and $15 \times 10^{4}$ spores $/ \mathrm{ml}$ in 2009, 2010, and 2011, and 0,30,60,90,120,150,180,210, and $240 \times 10^{3}$ spores $/ \mathrm{ml}$ in 2012) at anthesis (Feekes 10.5.1). SLB severity was recorded as mean percentage of diseased flag leaf area at the milky ripe growth stage (Feekes growth stage 11.1), whereas FHB index was scored as mean proportion of diseased spikelets per spike (sum of the proportion of diseased spikelets per spike divided by the total number of spikes sampled, included those with zero severity). Each bar represents the mean of 27 observations (three replications of nine plots) for SLB and 9 observations (three replications of three plots) for FHB index. 
Meta-analysis of the IND-yield relationship. Because of two low disease years in 2011 and 2012, data from 16 additional experiments conducted over a period of 11 years were included to provide a larger sample size as well as an overall wider range of IND and yield values for modeling the IND-yield relationship than the 4 years of data (YL09, YL10, YL11, and YL12) obtained from the experiments described above (Table 2; Fig. 2I). Results from linear mixed-model regression analysis of data from each individual experiment showed that, in general, the cultivar $\times$ IND interaction was not statistically significant (Table 2), suggesting that a common slope model may be appropriate for modeling the IND-yield relationship in most cases. To formally test the null

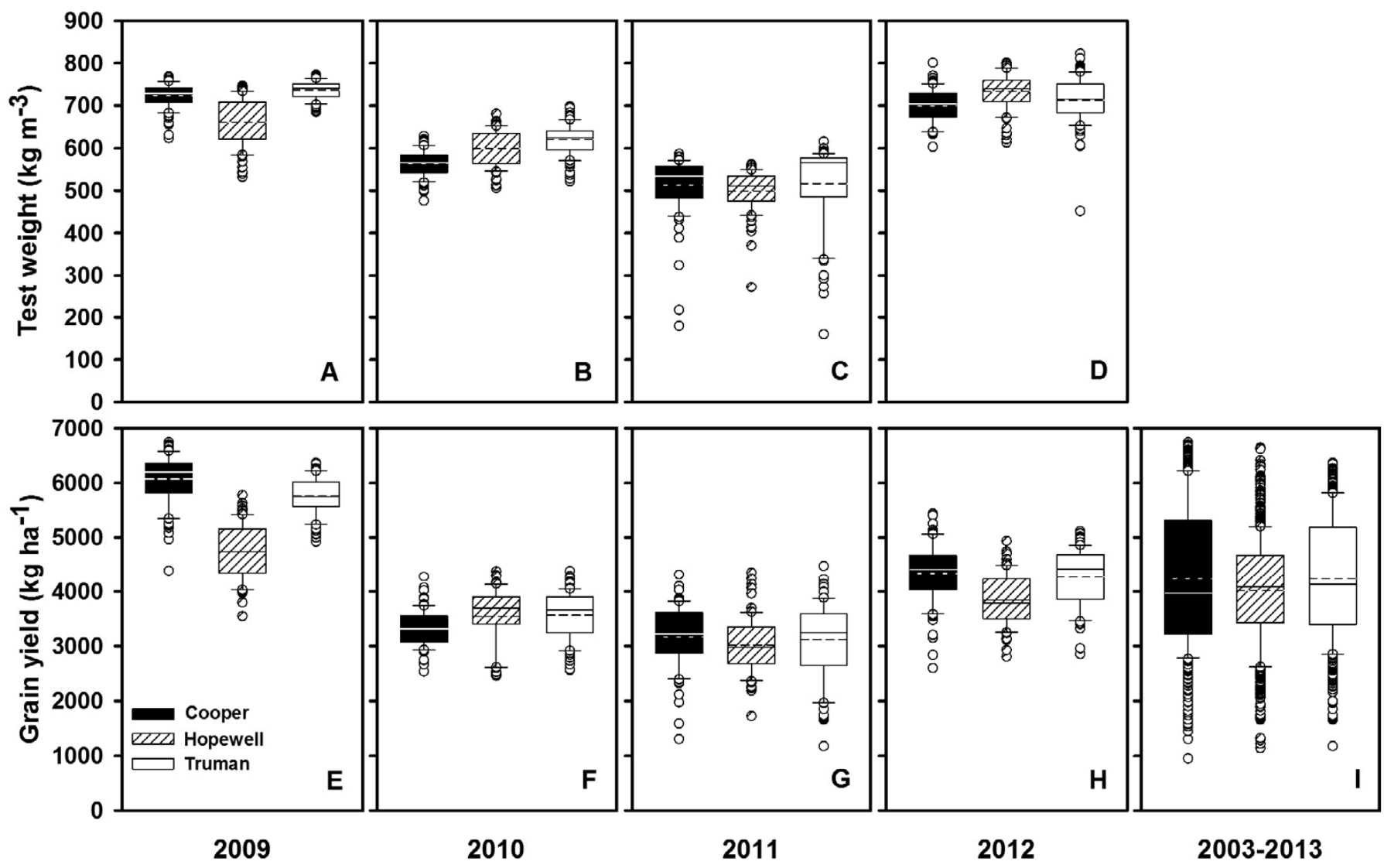

Fig. 2. Boxplots showing the distribution of A to $\mathbf{D}$, test weight (weight per unit volume) and $\mathbf{E}$ to $\mathbf{I}$, grain yield from plots of three soft red winter wheat cultivars (Cooper [moderate-high yield potential, and early maturing), Hopewell [moderate-high yield potential, and midseason], and Truman [moderate yield potential, and late maturing]) inoculated with Parastagonospora nodorum and Fusarium graminearum and affected by Stagonospora leaf blotch and Fusarium head bight. Broken and solid lines within the box represent the mean and median, respectively, while the top and bottom lines of the box represent the 75th and 25th percentiles of the data, respectively. Vertical bars extending beyond the boxes represent the 10th and 90th percentiles and circles indicate outliers. Numbers 2009 , 2010, 2011, and 2012 represent the years in which the experiments were conducted, whereas 2003-2013 indicates pooled data from 20 experiments conducted in Ohio from 2003 to 2013.

TABLE 3. Estimated regression coefficients and their 95\% confidence intervals for relationships between test weight and Fusarium head blight (FHB) index (the predictor) as influenced by soft red winter wheat cultivar and Stagonospora leaf blotch (SLB) severity classes and between grain yield and FHB index from field experiments conducted in Wooster and Hoyteville, $\mathrm{OH}^{\mathrm{a}}$

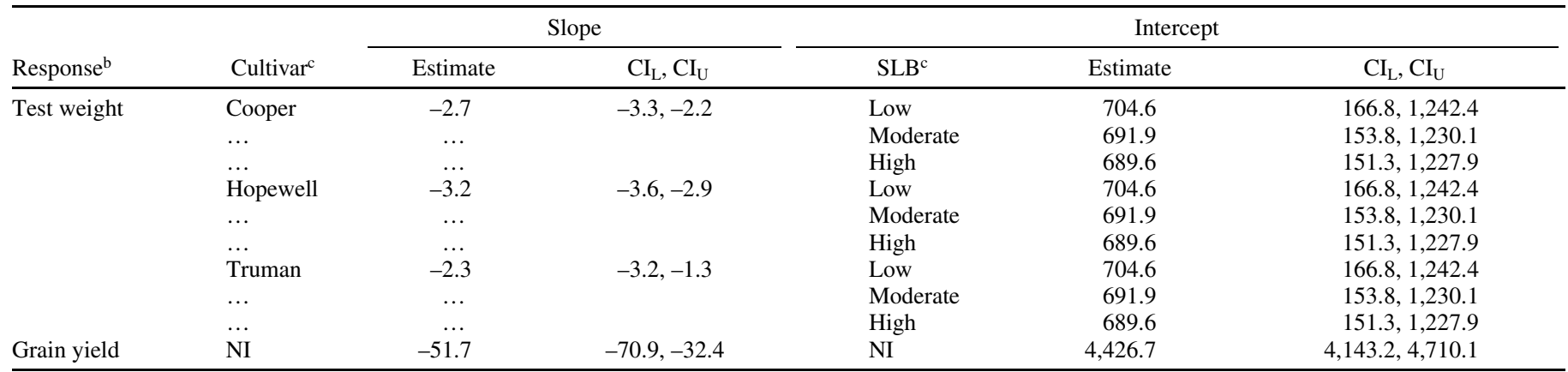

${ }^{a}$ Estimated regression slopes and intercepts and the lower and upper limits of their $95 \%$ confidence intervals $\left(\mathrm{CI}_{\mathrm{L}}\right.$ and $\mathrm{CI}_{\mathrm{U}}$, respectively). These statistics were estimated from linear mixed-model regression analysis for test weight and bivariate random-effects meta-analysis for grain yield.

${ }^{\mathrm{b}}$ Grain yield $\left(\mathrm{kg} \mathrm{ha}^{-1}\right)$ and test weight (grain weight per unit volume $\left[\mathrm{kg} \mathrm{m}^{-3}\right]$ ).

${ }^{c}$ Cultivar = Cooper (susceptible to SLB and FHB, moderate-high yield potential, and early-maturing), Hopewell (susceptible to SLB and FHB, moderate-high yield potential, and midseason), and Truman (moderately resistant to SLB and FHB, moderate yield potential, and late-maturing). SLB $=$ SLB as a class variable (low, moderate, and high) based on categories of inoculum density (none, low, and high), and NI = cultivar and SLB severity classes were not included in the final model because results from the analyses showed that these factors did not have a significant effect on the FHB index-yield relationship. 
hypothesis of no interaction between cultivar and IND (i.e., no effect of cultivar on the decline in yield with unit increase in IND), a meta-analysis was conducted using the individual $P$ values (Table 2) to test the global significance of this interaction at $\alpha=5 \%$. The Fisher method (7) was used for this analysis, with the $\chi^{2}$ test statistic and global $P$ value computed using a macro in SAS (L. V. Madden, unpublished data). Based on the $\chi^{2}$ test with $2 k$ degrees of freedom (where $k=17$, the number of $P$ values being combined), the global $P$ value was 0.390 (failing to reject the null hypothesis of no interaction), confirming the appropriateness of the common-slope model for the IND-yield relationship. This indicated that, overall, the rate of yield decrease per unit increase in IND was not influenced by the cultivars used in this study.

Estimated slopes and intercepts from the regression analyses from individual studies are shown in Figure 4. These estimates varied among experiments and cultivars (at least numerically), with intercepts of 2,686.3 to $6,413.4,1,275.6$ to 5,914.0, and 2,865.3 to $5,921.5 \mathrm{~kg} \mathrm{ha}^{-1}$ for Cooper, Hopewell, and Truman, respectively (Fig. 4A). The corresponding ranges for estimated slopes were -176.9 to $16.8,-256.9$ to 38.8 , and -211.1 to $25.1 \mathrm{~kg}$ $\mathrm{ha}^{-1} \%^{-1}$ for Cooper, Hopewell, and Truman, respectively (Fig. 4B). The estimated slopes were negative in $80 \%$ of the experiment-cultivar combinations (considered as separate studies here) (Fig. 4B). In general, studies with positive slopes, as well as those with high negative slopes, had relatively large standard errors (se) (Fig. 4B). Consequently, by definition, these extreme effect sizes received relatively small weights $\left(1 / \mathrm{se}^{2}\right)$ in the meta-analysis and, as such, contributed less to the estimate of the overall effect size in the meta-analysis than those with small standard errors (large weight).

The overall mean slope and intercept across the population of studies from the bivariate random-effects meta-analysis $(-51.7 \mathrm{~kg}$ $\mathrm{ha}^{-1} \%{ }^{-1}$ and $4,426.7 \mathrm{~kg} \mathrm{~m}^{-3}$, respectively) were significantly different from zero, based on the standard normal test $(P<0.001)$ (Table 3 ). The standard errors of the estimated effect sizes were 9.8 for the slope and 144.6 for the intercept. The among-study variances for the mean slope and intercept were large $(3,764$ and 902,347 , respectively) and significantly different from zero, based on the standard normal test. Results from the fit of the model with cultivar as a moderator showed that cultivar did not have a significant effect on the overall magnitude of the yield reduction per unit increase in IND (mean slope) $\left(\chi^{2}=0.16 ; P=0.92\right)$ or the population mean intercept $\left(\chi^{2}=0.93 ; P=0.63\right)$. The inclusion of cultivar as a moderator variable in the model did not reduce the among-study variance of the estimated parameters. Therefore, the final model for IND-yield relationship across all cultivars and studies was written using the population average parameters as $y=4,426.7-51.7$ (IND).

Prediction and relative yield and test weight. Because the primary focus of this research was grain yield and quality losses due to FHB, the IND-yield and IND-test weight models were used to predict the levels of IND at which a certain absolute amount of yield and test weight reduction was expected to occur. This was done using inverse prediction, as described by Madden and Paul (23), by rearranging the generic equation $y=a+b$ (IND) (with subscripts suppressed for ease of expression) and solving

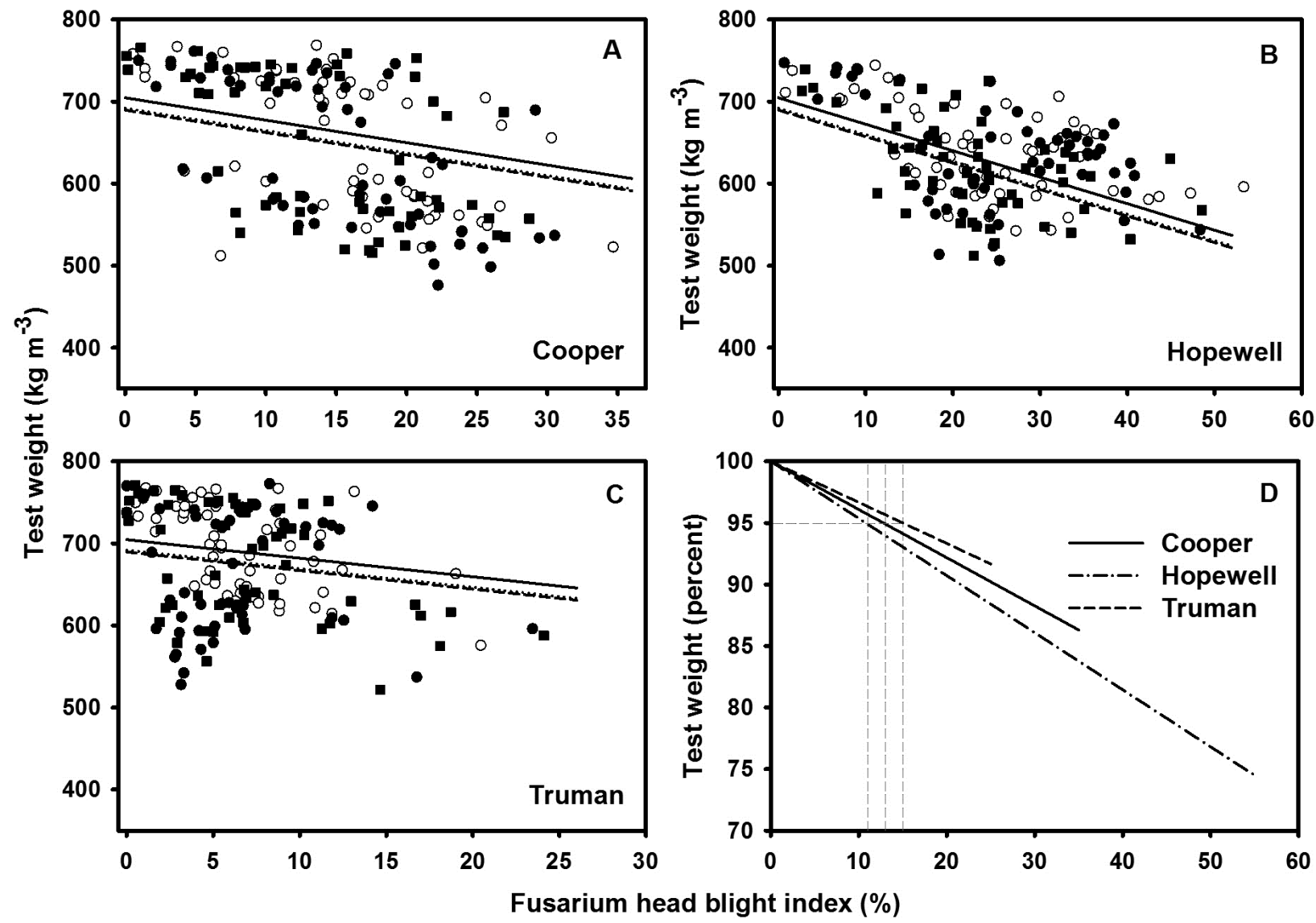

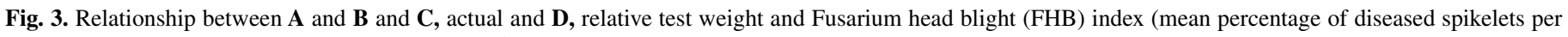

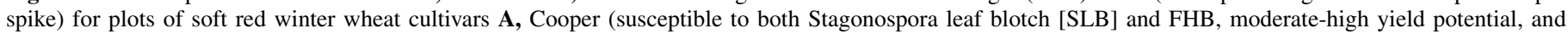

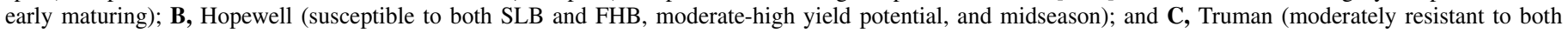

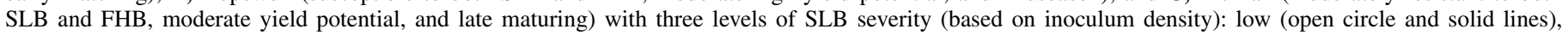

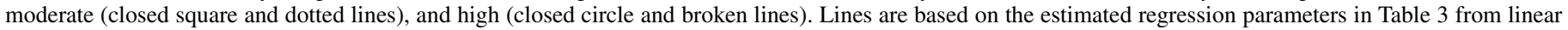

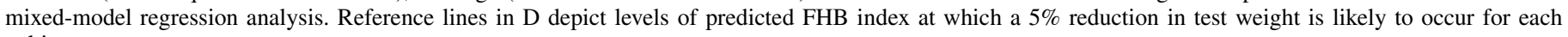
cultivar. 
for IND (see Appendix). Let $b_{\text {(yld) }}$ and $b_{(\mathrm{tw})}$ be the slopes for yield and test weight, respectively, and $a_{(\mathrm{yld})}$ and $a_{(\mathrm{tw})}$ the corresponding intercepts. Using the parameter estimates in Table 3 , the IND level at which a $50 \mathrm{~kg} \mathrm{~m}^{-3}$ reduction in test weight was estimated to occur for Cooper was $19 \%=(654.6-704.6) /(-2.7)$. For Hopewell and Cooper, cultivars with higher and lower negative $b_{(\mathrm{tw})}$ ( -3.2 and -2.3 , respectively), the corresponding IND values were 16 and $22 \%$.

Similarly, based on estimated $b_{(\mathrm{yld})}$ and $a_{\text {(yld) }}$ from the metaanalysis $\left(-51.7 \mathrm{~kg} \mathrm{ha}^{-1} \%^{-1}\right.$ and $4,426.7 \mathrm{~kg} \mathrm{~m}^{-3}$, respectively) (Table 3), the IND level at which a $1 \mathrm{MT} \mathrm{ha}^{-1}$ yield loss occurred was $19 \%=(3,426.7-4,426.7) /(-51.7)$ (Fig. 5A, insert). As expected, this IND value was the same for all three cultivars evaluated in this study, regardless of their resistance to FHB, maturity, or yield potential. Because the effect of cultivar on the population parameter estimates, $\bar{a}$ and $\bar{b}$ (referred to here as $a_{\text {(yld) }}$ and $\left.b_{(\mathrm{yld})}\right)$, from the meta-analysis was not significant, any given absolute reduction in grain yield is expected to occur at the same level of IND for Hopewell, Cooper, and Truman.

Because of the inherent difference among trials (years, locations, cultivars, and so on), relative yield and test weight (as a percentage) responses are often used as a standardized way of representing reductions in grain yield or quality, allowing comparisons among experiments. One can obtain the relative yield and test weight on a percentage scale by dividing both sides of the generic equation $y=a+b$ (IND) by the intercept ( $a$, yield or test weight in the absence of disease under a given set of conditions) and then multiplying by 100 (23). Using the parameters in Table 3, the rates of reduction in relative test weight at the low SLB level were $-0.38 \%^{-1}$ for Cooper $([-2.7 \times 100] / 704.6),-0.45 \%^{-1}$ for Hopewell, and $-0.32 \%^{-1}$ for Truman. Slightly higher rates of relative loss (higher negative values) were observed at the high SLB levels $\left(-0.39,-0.46\right.$, and $-0.33 \%^{-1}$ for Cooper, Hopewell and Truman, respectively). For yield, with $b_{\text {(yld) }}=-51.7 \mathrm{~kg} \mathrm{ha}^{-1} \%^{-1}$ and $a_{\text {(yld) }}=$ $4,426.7 \mathrm{~kg} \mathrm{~m}^{-3}$, the rate of reduction in relative yield per unit increase in IND was $-1.17 \%^{-1}$.

Relative test weight and yield are shown in Figures 3D and 5B. For instance, at $20 \%$ IND, relative test weight was $92 \%$ for Cooper, $91 \%$ for Hopewell, and $93 \%$ for Truman (Fig. 3D). A 5\% reduction in test weight (from 100 to 95\%) (Fig. 3D, horizontal reference line) was estimated to occur at IND values of 13,11 , and $15 \%$ for Cooper, Hopewell, and Truman, respectively (Fig. $3 \mathrm{D}$, vertical reference lines). For grain yield, at an IND of $35 \%$, relative yield was estimated at $60 \%$. A $20 \%$ yield loss (100 to $80 \%$ ) (Fig. 5B, horizontal reference line) was predicted to occur at $18 \%$ IND (Fig. 5B, insert).
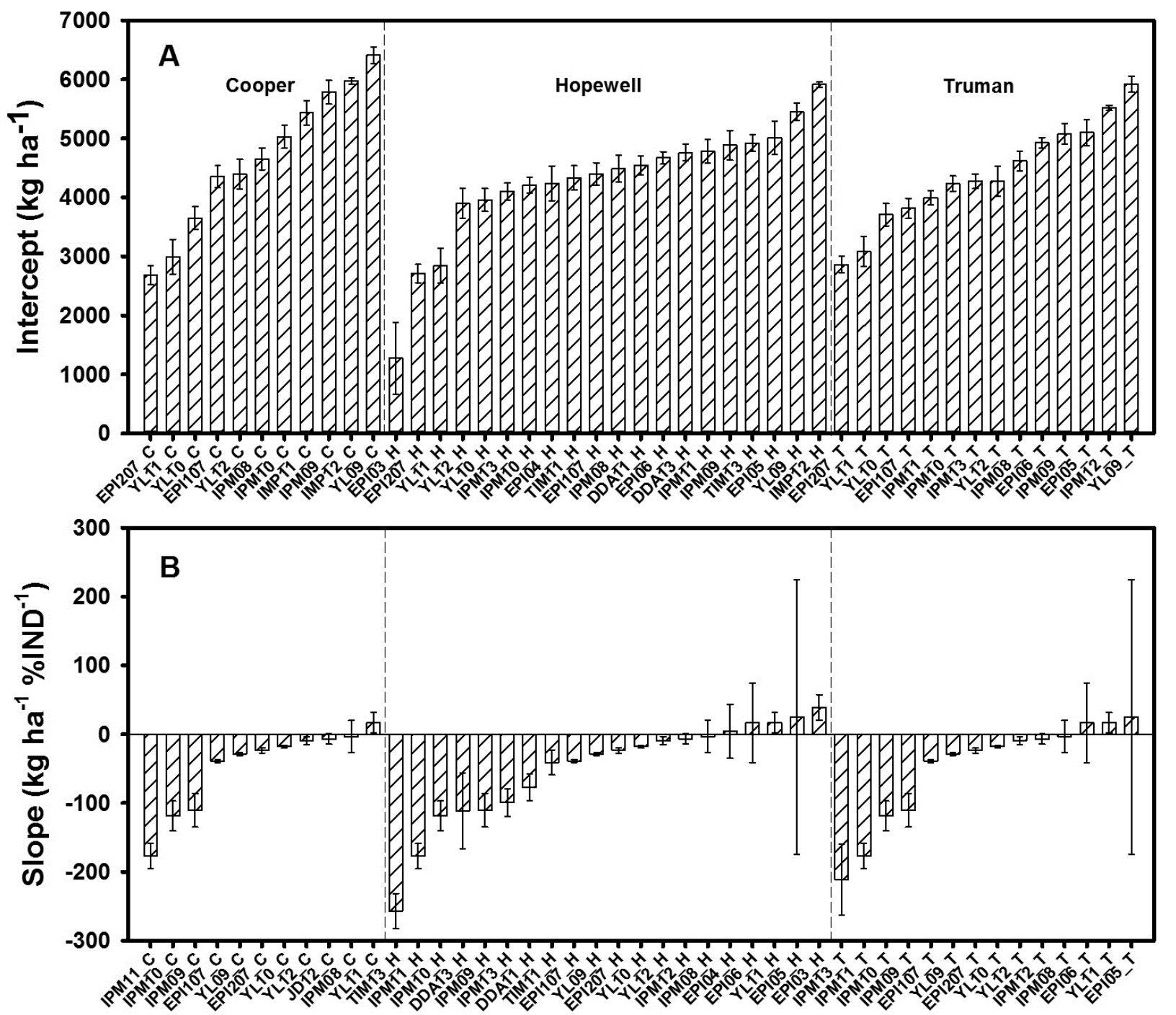

Fig. 4. Estimated A, intercepts and $\mathbf{B}$, slopes from linear mixed-model regression analysis of the relationship between grain yield and Fusarium head blight (FHB) index (IND) (mean percentage of diseased spikelets per spike) for soft red winter wheat cultivars Cooper (susceptible to FHB, moderate-high yield potential, and early maturing), Hopewell (susceptible to FHB, moderate-high yield potential, and midseason), and Truman (moderately resistant to FHB, moderate yield potential, and late maturing) from different field experiments conducted in Ohio. Vertical broken lines separate the parameters for the three cultivars. Error bars are standard error of the estimated parameters. 


\section{DISCUSSION}

The fact that Fusarium head blight (as well as other diseases) affects wheat grain yield and test weight (as well as other grain quality traits) has been well documented $(25,26)$. Yield in wheat (in terms of weight or volume per area) is a function of the number of tillers and grains produced per unit area which, in turn, is influenced by the number of spikelets per spike, kernels per spikelet, kernel size and weight, and interactions among these components (43). Test weight is primarily a function of the size of the grains. There are numerous reports in the literature of the effect of FHB on components of yield and test weight $(3,44,51)$ but very few provide quantitative estimates of losses due to this disease based on formal analyses of the FHB-yield or FHB-test weight relationships. For instance, in reviewing the economic impact of FHB on the wheat industry, Windels (50) and Parry et al. (30) reported losses in parts of the United States, India, China, and Europe in terms of percent yield reduction relative to "normal" FHB-free yield in the affected regions, but none of these reports provided information about the nature or form of the functional relationship between FHB and yield and factors affecting this relationship.

In this study, we gathered data from a series of field experiments conducted from 2003 to 2013 and developed models for IND-test weight and IND-yield relationships. We further evaluated the effects of cultivar characteristics (based on three cultivars that are standard references in terms of maturity, FHB resistance, and yield potential among soft red winter wheat in Ohio and neighboring states) and ordinal categories of SLB intensity on these relationships. Our results provide evidence indicating that, as expected, both yield and test weight decreased as IND increased. There was also evidence of the effects of cultivar and SLB on the IND-test weight relationship but not the IND-yield relationship. The slope of the IND-test weight regression lines was affected by cultivar, and the intercept but not the slope of the line was affected by SLB. Test weight was significantly higher in the non- $P$. nodorum-inoculated treatments (i.e., low SLB category) than in inoculated treatments. This is comparable with what Milus and Chalkley (28) observed in Arkansas while studying this same disease.

The magnitude of the mean difference in test weight among SLB categories in this study was consistent across IND levels (nonsignificant SLB $\times$ IND interaction), suggesting that, although both FHB and SLB affect test weight $(5,25,26,28)$, SLB did not affect the magnitude of the test weight reduction per unit increased in IND. This is probably due to the fact that the two diseases affect different plants parts (Stagonospora glume blotch levels were very low in all years of this study) and, as a result, likely impacted the size and weight of the wheat kernels, important components of test weight, at different times during the grain development process. We hypothesize that, because SLB affects the leaf and probably reduces the green leaf area before FHB reduced the green area of the spike, the former disease likely reduced the baseline test weight, which then suffered further reduction once FHB developed. The relative importance of the leaves and spikes as sources of nutrients for grain fill, as well as research on the effect of green leaf area duration on test weight, support this hypothesis. For instance, Gooding (16) observed a significant positive relationship between green flag leaf area and test weight (called specific weight) but the strength of this relationship decreased and was less reliable when green flag leaf area was extended well beyond anthesis. Gooding (16) suggested that the late-season "breakdown" in the green flag leaf area-test weight relationship was due in part to a decline in the "packing density" of shriveled grain and reduction of grain protein content due to late-season diseases (such as FHB), among other factors.

For a given baseline level of SLB (and, consequently, baseline test weight; based on the SLB effect on the intercept), the rate of test weight reduction per unit increase in IND was greater for Hopewell, the FHB-susceptible, midseason cultivar, than for Cooper and Truman. This likely reflects differences among the cultivars in terms of the rate at which the size of the kernels decreased as IND increased, as a result of differences in resistance to FHB. Others have alluded to the effect of cultivar resistance on kernel weight reduction in response to $\mathrm{FHB}$, showing that the reduction (in terms of percent relative to FHB-free references) tended to be lower for more resistant cultivars than for susceptible cultivars (51). When the cultivars evaluated in our study were compared in terms of relative test weight response, an approach that allows for cultivar comparison after adjusting for baseline (intercept) effects, a fixed percent reduction in test weight was estimated to occur at a slightly higher level of IND for Truman, the moderately resistant cultivar, than for Hopewell and Cooper, suggesting an effect of resistance on the IND-test weight relationship, and possibly greater test weight "tolerance" in the moderately resistant cultivar. In fact, due to the relatively narrow range of mean index values observed for Truman (0 to 25\%) as a result of its resistance, this cultivar never suffered more than an $8 \%$ reduction in test weight in this study. By contrast, Hopewell, the cultivar with the widest range of mean index (0 to 55\%), suffered more than a $25 \%$ reduction in test weight at the highest observed mean IND level.

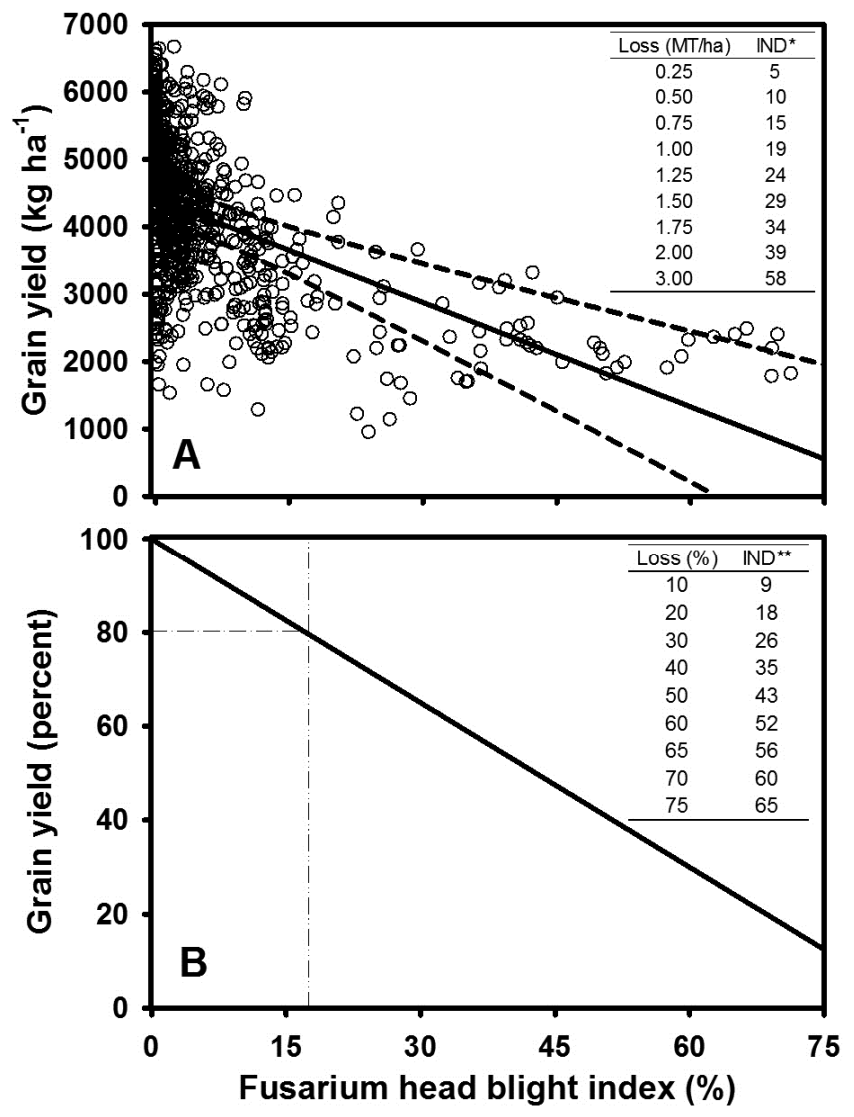

Fig. 5. Relationship between $\mathbf{A}$, actual and $\mathbf{B}$, relative grain yield and Fusarium head blight index (IND) (mean proportion of diseased spikelets per spike) for soft red winter wheat. Lines are based on the estimated mean regression parameters (effect sizes) in Table 3 from bivariate random-effects meta-analysis of individual parameters from 45 studies (cultivar-experiment combinations). Lines in A represent predicted yield (solid line) and its $95 \%$ confidence interval (broken lines). Points in A represent individual observations (pairs of IND and yield data points) for each experimental unit from 20 field experiments conducted in Wooster and Hoyteville, $\mathrm{OH}$ from 2003 to 2013. Inserts in A and B show predicted index levels (IND* and IND ${ }^{* *}$ ) at which a certain amount of absolute (A) and relative (B) yield losses are expected to occur. Reference lines in B show IND ${ }^{* *}$ at which a $20 \%$ yield loss is expected to occur. 
The levels of SLB severity observed in this study were sufficient to affect test weight but not grain yield. Neither the main effect of SLB nor its interactions with FHB and cultivar had significant effects on yield in the four experiments (years) of this study in which $P$. nodorum inoculation treatments were applied. One may speculate that, although the effect of $P$. nodorum inoculum density was statistically significant, resulting in different levels of mean SLB severity, the range and absolute levels of SLB were likely not sufficient to impact yield on a volumetric basis. Without such ranges, it is particularly difficult to characterize the true form of any disease-yield relationship $(15,21,22)$. For practical reasons (particularly space limitation), only three levels of $P$. nodorum inoculation treatments were used in this study, with the hope of obtaining a range of SLB levels after combining the data across experiments. However, for both the individual years and the pooled data, the effect of SLB on yield was not statistically significant. This was true even in 2010, when the mean level of SLB severity was as high as $40 \%$ for Hopewell.

Another possible explanation for the lack of SLB effect on yield under the conditions of this study is the fact the onset of this disease was relatively late in all 4 years of the study. Although inoculations were done at Feekes GS 9, SLB only reached the flag leaf at or after anthesis. As discussed above, based on green flag leaf area duration, reduction of the flag leaf health after anthesis has less of an effect of yield components than reduction before anthesis (16). Although the flag leaf is well known for its importance in grain fill, results from defoliation studies showed that under certain conditions post-anthesis removal of this leaf only had a minor effect on grain yield in wheat $(1,2)$. There is also evidence suggesting that other photosynthetically active plant parts (spikes and stems in particular) and remobilization of nutrients may compensate for damage to the flag leaf, leading to minimal reduction in yield.

Based on data from 45 studies (cultivar-experiments) collected over an 11-year period, there was, in general, a significant negative straight-line relationship between IND and grain yield. This is consistent with the findings reported by Madden and Paul (23) and Salgado et al. $(40,41)$ in terms of the nature of the functional relationship between IND and yield. However, there was considerable variation in the estimated intercepts and slopes among the studies. Consequently, bivariate random-effects meta-analytical models were fitted to the data to estimate overall populationmean slope and intercept, quantify the random effect of study on the estimates, and determine whether the population-mean parameters varied significantly among cultivars.

The population mean intercept and slope from the meta-analysis were $4,426.7 \mathrm{~kg} \mathrm{ha}^{-1}$ and $-51.7 \mathrm{~kg} \mathrm{ha}^{-1} \% \mathrm{IND}^{-1}$, respectively. The population-mean intercept estimated here is very similar to that reported by Madden and Paul (23) for winter wheat (4.57 $\mathrm{MT} / \mathrm{ha}$ ) based on random-coefficient mixed-model analysis of data collected from multiple wheat-growing regions across the United States. The population-average slope is similar to that reported by Salgado et al. (41) $\left(-52.4 \mathrm{~kg} \mathrm{ha}^{-1} \% \mathrm{IND}^{-1}\right)$ from a study to evaluate the effect of different FHB management programs on FHB IND-yield relationship. However, the estimated slopes reported here and by Salgado et al. (41) are steeper than reported by Madden and Paul (23), likely reflecting differences among the data sets used for model fitting in terms of the susceptibility of the cultivars planted and fungicide treatments applied. In the latter study, only susceptible cultivars were used, many plots were treated with a fungicide, and experiments were conducted over a wide range of environments (77 different experiments). Moreover, the differences in statistical methods may have also affected the results.

The $R^{2}$ index of Higgins and Thompson (17) from the metaanalyses was considerably larger than 1.5 for both effect sizes (data not shown), indicating that among-study variability had a major influence on the IND-yield relationship, thus justifying our decision to fit random-effects models. Therefore, two separate meta-analytical approaches were used to determine whether cultivar accounted for the slope and intercept heterogeneity among studies. The analysis based on the $P$ values (7) for the cultivar $\times$ IND interaction showed that cultivar had no effect on the INDyield regression slope. A similar conclusion was drawn from the mixed-effect meta-analysis of the estimated slopes with cultivar as a categorical moderator variable. Here, the fixed effect of cultivar on the population expected slope was not statistically significant $(P=0.92)$. Consequently, the inclusion of cultivar as a moderator variable in the meta-analytical did not reduce the among-study variability for the IND-yield regression slope. Thus, slopes were numerically but not statistically different among the cultivars, suggesting that cultivar did not affect the rate at which yield decreased per unit increased in IND. These results could be interpreted to mean that the rate of kernel size and weight reduction and starch and protein degradation in response to $F$. graminearum infection and FHB development were independent of cultivar characteristics (FHB resistance, maturity, and yield potential) under the conditions of this study.

Because the estimated slope was the same for the three cultivars, the predicted level of index at which yield loss of a fixed absolute amount was expected to occur was also the same. For instance, a 1-MT/ha reduction in yield was predicted to occur at an index of $19 \%$ for all three cultivars, regardless of maturity, FHB resistance, or yield potential. However, predicted yield loss in Truman, the moderately resistant cultivar, did not exceed 1 $\mathrm{MT} / \mathrm{ha}$ in this study because the maximum mean index for this cultivar did not reach $20 \%$. For the two susceptible cultivars, yield loss was predicted to exceed $3 \mathrm{MT} / \mathrm{ha}$ at the highest levels of observed index.

In this study, we successfully quantified the relationships between IND and test weight and IND and yield, and showed that cultivar affected the slope of the IND-test weight regression line, while the foliar disease SLB affected the intercept. However, the IND-yield relationship was stable across cultivars and SLB levels, but the magnitude of the among-study variances for the slope and intercept suggested that other unmeasured or unmeasurable factors affected this relationship. Our results suggest that it is possible to use the models developed in this study to predict yield loss on a relative scale (as a percentage, after adjusting for baseline yield). Here, the rate of reduction in relative yield per unit increase in IND $\left(-1.17 \%^{-1}\right)$ was comparable with those reported from studies conducted under vastly different environmental and crop-production conditions from those observed (or imposed) in this investigation. For instance, based on mean IND and yield data from fungicide efficacy experiments, Madden and Paul (23) estimated rates of relative yield loss of -0.99 and $-0.81 \%^{-1}$ for spring and winter wheat, respectively. Similarly, also based on data from fungicide efficacy experiments, but under European conditions, Willocquet et al. (48) reported a relative yield loss slope of $-1.1 \%^{-1}$. The similarity of these results bodes well for possible utilization of models from this study to estimate percent yield loss due to FHB and future application of these findings in analyses of the economic impact of FHB.

\section{APPENDIX}

Here, we provide further details pertaining to the models fitted to the grain yield and test weight data to quantify the effects of cultivar (CV) and SLB severity classes on the IND-yield and IND-test weight relationships. We also show how the resulting models were used to estimate grain yield and quality (test weight) losses on an absolute and relative scale, and to predict IND levels at which certain amounts of absolute and relative yield and test weight losses are expected to occur.

Linear mixed-model regression analyses were used to model the IND-yield and IND-test weight relationships as influenced by 
$\mathrm{CV}$ and SLB severity classes. For both responses, each experiment (each year) was first analyzed separately using PROC GLIMMIX of SAS (SAS Inc., Cary, NC) (20); then, the data were pooled for subsequent analyses. In fitting the models, IND on the original percentage scale was used as a continuous covariate, whereas $\mathrm{CV}$ and Parastagonospora nodorum inoculation treatment (none, medium, and high), used here to represent different SLB severity classes (low, moderate, and high), were categorical fixed effects. Year, block, and all interactions involving year and block were treated as random effects, and separate analyses were performed for each response by fitting the following models:

$$
\begin{gathered}
y_{i j l m}=\theta+\alpha_{i}+\beta_{j}+(\alpha \beta)_{i j}+\delta X_{m}+\Delta_{i} X_{m}+\gamma_{j} X_{m}+\vartheta_{i j} X_{m} \\
+b_{l}+\alpha b_{i l}+\beta(\alpha b)_{i j l}+e_{i j l m}
\end{gathered}
$$

for each year (experiment), or

$$
\begin{aligned}
y_{i j k l m}= & \theta+\alpha_{i}+\beta_{j}+(\alpha \beta)_{i j}+\delta X_{m}+\Delta_{i} X_{m}+\gamma_{j} X_{m}+\vartheta_{i j} X_{m} \\
& +\varphi_{k}+b(\varphi)_{k l}+\alpha(b \varphi)_{i k l}+\beta(\alpha b \varphi)_{i j k l}+e_{i j k l m}
\end{aligned}
$$

for the pooled data, where $y_{i j l m}$ is the response (yield and test weight); $\theta$ is the constant (intercept); $\alpha_{i}$ is the effect of the $i$ th $\mathrm{CV}$; $\beta_{j}$ is the effect of the $j$ th SLB severity class; $(\alpha \beta)_{i j}$ is effect of the $i$ th $\mathrm{CV} \times j$ th SLB severity class interaction; $X_{m}$ is the $m$ th observation of the covariable IND; $\delta$ is the effect of the covariable; $\Delta_{i}$ is the interaction effect of the covariable and $\mathrm{CV} ; \gamma_{j}$ is the interaction effect of the covariable and SLB severity class; $\vartheta_{i j}$ is the interaction effect of the covariable, CV, and SLB severity class; $b_{l}$ is the effect of the $l$ th block; $\alpha b_{i l}$ is the effect of $i$ th $\mathrm{CV} \times l$ th block interaction; $\beta(\alpha b)_{i j l}$ is the effect $j$ th SLB severity class within the $i$ th $\mathrm{CV}$ within the $l$ th block; and $e_{i j l m}$ is the residual. For the pooled data model (A2), $y_{i j k l m}$ is the response; $\varphi_{k}$ is the effect of the $k$ th year; $b(\varphi)_{k l}$ is the effect of the $l$ th block within the $k$ th year; $\alpha(b \varphi)_{i k l}$ is the effect of the $i$ th $\mathrm{CV}$ within the $l$ th block within the $k$ th year; $\beta(\alpha b \varphi)_{i j k l}$ is the effect of the $j$ th SLB severity class within the $i$ th $\mathrm{CV}$ within the $l$ th block within the $k$ th year; and $e_{i j k l m}$ is the residual. In both equations, the $m$ subscript refers to each unique covariable observation (for example, this represents the different plots of each FHB inoculum density within each block and year). Models were initially fitted with all of the terms and then nonsignificant terms $(P>0.05)$ were removed in a stepwise fashion, beginning with the interactions.

Inverse prediction, as described by Madden and Paul (23), was used to predict the levels of IND $\left(I N D^{*}\right)$ at which a certain absolute amount of yield and test weight reductions were expected to occur by rearranging the generic equation $y=a+b$ (IND) (with subscripts suppressed for ease of expression) and solving for IND (referred to here as $I N D^{*}$ ) as

$$
I N D^{*}=\left(y^{*}-a\right) / b
$$

where $y^{*}$ is the specific grain yield or test weight of interest (the level reached after a reduction) and $a$ and $b$ are the intercept and slope, respectively.

Relative yield and test (as a percentage) responses (symbolized as $w$ ) were estimated by dividing both sides of the generic equation $y=a+b$ (IND) by the intercept ( $a$ ) and then multiplying by 100 (23). Relative response was estimated as

$$
w=100+(100 b / a) I N D
$$

where $(100 \mathrm{~b} / \mathrm{a})$ is the rate of reduction in relative test weight or yield per unit increase in IND. Then, using inverse-prediction to solve equation A4 for IND, the estimated level of IND (referred to here as $I N D^{* * *}$ ) at which a certain percentage test weight (or yield) loss is likely to occur was estimated as

$$
I N D^{* *}=(w-100) /(100 b / a)
$$

where all variables are as described above.

\section{ACKNOWLEDGMENTS}

Salaries and research support for J. D. Salgado, P. A. Paul, and L. V. Madden were provided by state and federal funds to the Ohio Agricultural Research and Development Center. We thank K. Willyerd, M. Wallhead, K. Davies, W. Bardall, R. Barry, and J. Heller for assisting with establishment, maintenance, and harvest of research plots and treatment application; and D. D'Angelo and C. Li for contributing to the experiments used in the meta-analysis. This investigation is based upon work supported by the United States Department of Agriculture through the U.S. Wheat \& Barley Scab Initiative (agreement number 59-0206-9-071). Any opinions, findings, conclusions, or recommendations expressed in this publication are those of the authors and do not necessarily reflect the view of the United States Department of Agriculture.

\section{LITERATURE CITED}

1. Aggarwal, P. K., Fischer, R. A., and Liboon, S. P. 1990. Source-sink relation and effects of post anthesis canopy defoliation in wheat at low latitudes. J. Agric. Sci. 114:93-99.

2. Ahmadi, A., Joudi, M., and Janmohamadi, M. 2009. Late defoliation and wheat yield: Little evidence of post anthesis source limitation. Field Crop Res. 113:90-93.

3. Bechtel, D. B., Kaleikau, L. A., Gaines, R. L., and Seitz, L. M. 1985. The effects of Fusarium graminearum on wheat kernels. Cereal Chem. 62:191-197.

4. Beuerlein, J., Lipps, P., and Lentz, E 2005. Small Grain Production. Ohio Agronomy Guide, 14th ed. Ohio State Univ. Ext. Bull. 472:72-88.

5. Bhathal, J. S., Loughman, R., and Speijers, J. 2003. Yield reduction in wheat in relation to leaf disease from yellow $(\tan )$ spot and Septoria nodorum blotch. Eur. J. Plant Pathol. 109:435-443.

6. Blandino, M., Haidukowski, M., Pascale, M., Plizzari, L., Scudellari, D., and Reyneri, A. 2012. Integrated strategies for the control of Fusarium head blight and deoxynivalenol contamination in winter wheat. Field Crop Res. 133:139-149.

7. Borenstein, M., Hedges, L. V., Higgins, J. P. T., and Rothstein, H. R. 2009. Introduction to Meta-Analysis. John Wiley \& Sons, Chichester, UK.

8. Champeil, A., Dore, T, and Fourbet, J. F. 2004. Fusarium head blight: Epidemiological origin of the effects of cultural practices on head blight attacks and the production of mycotoxins by Fusarium in wheat grains. Plant Sci. 166:1389.

9. D'Angelo, D. L. 2013. Effects of fungicide chemistry and application timing on Fusarium head blight and deoxynivalenol in soft red winter wheat. M.S. thesis, Department of Plant Pathology, The Ohio State University, Columbus.

10. D'Angelo, D. L., Bradley, C. A., Ames, K. A., Willyerd, K. T., Madden, L. V., and Paul, P. A. 2014. Efficacy of fungicide applications during and after anthesis against Fusarium head blight and deoxynivalenol in soft red winter wheat. Plant Dis. 98: 1387-1397.

11. Edwards, S. G., and Godley, N. P. 2010. Reduction of Fusarium head blight and deoxynivalenol in wheat with early fungicide applications of prothioconazole, Food Addit. Contam. 27:629-635.

12. Engle, J. S. 2005. Pathogenic characterization, distribution in Ohio and wheat genotype reaction to Stagonospora nodorum and Pyrenophora tritici-repentis. Ph.D. dissertation, The Ohio State University, Columbus.

13. Engle, J. S., Lipps, P. E., and Minyo, R. J., Jr. 2006. Reaction of commercial soft red winter wheat cultivars to Stagonospora nodorum in the greenhouse and field. Plant Dis. 90:576-582.

14. Eyal, Z., Scharen, A. L., Prescott, J. M., and van Ginkel, M. 1987. The Septoria Diseases of Wheat: Concepts and Method of Disease Management. CIMMYT, Mexico, D.F.

15. Gaunt, R. E. 1995. The relationship between plant disease severity and yield. Annu. Rev. Phytopathol. 1995 33:119-114.

16. Gooding, M. J. 2007. Influence of foliar diseases and their control by fungicides on grain yield and quality in wheat. Pages 557-565 in: Wheat Production in Stressed Environments. H. T. Buck, J. E. Nisi, and N. 
Salomón, eds. Springer, The Netherlands.

17. Higgins, J. P. T., and Thompson, S. G. 2002. Quantifying heterogeneity in a meta-analysis. Stat. Med. 21:1539-1558.

18. Kriss, A. B., Paul, P. A., and Madden, L. V. 2010. Climate patterns as predictors of Stagonospora nodorum glume blotch in Ohio. (Abstr.) Phytopathology 102:S4.65.

19. Li, C. 2009. The effects of fungicides and cultivar resistance on associations among Fusarium head blight, deoxynivalenol, and fungal colonization of wheat grain. M.S. thesis, Department of Plant Pathology, The Ohio State University, Columbus.

20. Littell, R. C., Milliken, G. A., Stroup, W. W., Wolfinger, R. D., and Schabenberger, O. 2006. SAS for Mixed Models, second ed. SAS Institute Inc., Cary, NC.

21. Madden, L. V., Hughes, G., and van den Bosch, F. 2007. The Study of Plant Disease Epidemics. American Phytopathological Society, St. Paul, MN.

22. Madden, L. V., and Nutter, F. W., Jr. 1995. Modeling crop losses at the field scale. Can. J. Plant Pathol. 17:124-137.

23. Madden, L. V., and Paul, P. A. 2009. Assessing heterogeneity in the relationship between wheat yield and Fusarium head blight intensity using random-coefficient mixed models. Phytopathology 99:850-860.

24. Madden, L. V., and Paul, P. A. 2011. Meta-analysis for evidence synthesis in plant pathology: An overview. Phytopathology 101:16-30.

25. McMullen, M., Bergstrom, G., De Wolf, E., Dill-Macky, R., Hershman, D., Shaner, G., and Van Sanford, D. 2012. A unified effort to fight an enemy of wheat and barley: Fusarium head blight. Plant Dis. 96:17121728.

26. McMullen, M., Jones, R., and Gallenburg, D. 1997. Scab of wheat and barley: A re-emerging disease of devastating impact. Plant Dis. 81:13401348 .

27. Mesterhazy, A., Tóth, B., Varga, M., Bartók, T., Szabó-Hevér, A., Farády, L., and, Lehoczki-Krsjak, S. 2011. Role of fungicides, application of nozzle types, and the resistance level of wheat varieties in the control of Fusarium head blight and deoxynivalenol. Toxins 11:1453-1483.

28. Milus, E. A., and Chalkley, D. B. 1997. Effect of previous crop, seedborne inoculum, and fungicides on development of Stagonospora blotch. Plant Dis. 81:1279-1283.

29. Nishio, Z., Takata, K., Ito, M., Tanio, M., Tabiki, T., Yamauchi, H., and Ban, T. 2010. Deoxynivalenol distribution in flour and bran of spring wheat lines with different levels of Fusarium head blight resistance. Plant Dis. $94: 335-338$

30. Parry D. W., Jenkinson P., and McLeod L. 1995. Fusarium ear blight (scab) in small grain cereals-A review. Plant Pathol. 44:207-238.

31. Paul, P. A., El-Allaf, S. M., Lipps, P. E., and Madden, L. V. 2003. Development of Fusarium head blight of winter wheat in Ohio as influenced by planting date, cultivar maturity, and inoculum level. Pages 156-159 in: Proc. Natl. Fusarium Head Blight Forum. S. M. Canty, J. Lewis, L. Siler, and R. W Ward, eds. Michigan State University, East Lansing.

32. Paul, P. A., El-Allaf, S. M., Lipps, P. E., and Madden, L. V. 2005. Relationships between incidence and severity of Fusarium head blight on winter wheat in Ohio. Phytopathology 95:1049-1060.

33. Paul, P. A., Lipps, P. E., Hershman, D. E., McMullen, M. P., Draper, M. A., and Madden, L. V. 2008. Efficacy of triazole-based fungicides for Fusarium head blight and deoxynivalenol control in wheat: A multivariate meta-analysis. Phytopathology 98:999-1011.

34. Paul, P. A., Lipps, P. E., and Madden, L. V. 2006. Meta-analysis of regression coefficients for the relationship between Fusarium head blight and deoxynivalenol content of wheat. Phytopathology 96:951-961.
35. Paul, P. A., and Madden, L. V. 2014. Meta-analysis in plant disease epidemiology. In: Exercises in Plant Disease Epidemiology. K. L. Stevenson and M. J. Jeger, eds. American Phytopathological Society Press, St. Paul, MN.

36. Paul, P. A., McMullen, M. P., Hershman, D. E., and Madden, L. V. 2010. Meta-analysis of the effects of triazole-based fungicides on wheat yield and test weight as influenced by Fusarium head blight intensity. Phytopathology100:160-171.

37. Pestka, J. J. 2007. Deoxynivalenol: Toxicity, mechanisms and animal health risks. Anim. Feed Sci. Technol., 137:283-298.

38. Pirgozliev, S. R., Edwards, S. G., Hare, M. C., and Jenkinson, P. 2003. Strategies for the control of Fusarium head blight in cereals. Eur. J. Plant Pathol. 109:731-742.

39. Quaedvlieg, W., Verkley, G. J. M., Shin, H.-D., Barreto, R. W., Alfenas, A. C., Swart, W. J., Groenewald, J. Z., and Crous, P. W. 2013. Sizing up Septoria. Stud. Mycol. 75:307-390.

40. Salgado, J. D., Madden, L. V., and Paul, P. A. 2014. Efficacy and economics of integrating in-field and harvesting strategies to manage Fusarium head blight of wheat. Plant Dis. 98:1407-1421.

41. Salgado, J. D., Wallhead, M., Madden, L. V., and Paul, P. A. 2011. Grain harvesting strategies to minimize grain quality losses due to Fusarium head blight in wheat. Plant Dis. 95:1448-1457.

42. Shaner, G., and Buechley, G. 1995. Epidemiology of leaf blotch of soft red winter wheat caused by Septoria tritici and Stagonospora nodorum. Plant Dis. 79:928-938.

43. Slafer, G. A. 2007. Physiology of determination of major wheat yield components. Pages 557-565 in: Wheat Production in Stressed Environments. H. T. Buck, J. E. Nisi, and N. Salomón, eds. Springer, The Netherlands.

44. Snijders C. H. A., 1990. Genetic variation for resistance to Fusarium head blight in bread wheat. Euphytica 50:171-179.

45. Solomon, P., Lowe, R., Tan, C. T., Water, O., and Oliver, R. 2006 Stagonospora nodorum: Cause of Stagonospora nodorum blotch of wheat. Mol. Plant Pathol. 7:147-156.

46. Stack, R. W., and McMullen, M. P. 1998. A visual scale to estimate severity of Fusarium head blight in wheat. NDSU Extension Service: Small Grains Publications. Online Publication PP-1095. http://www. ag.ndsu.edu/pubs/plantsci/smgrains/pp1095

47. Wegulo, S. N., Bockus, W. W., Hernandez Nopsa, J., De Wolf, E. D., Eskridge, K. M., Peiris, K. H. S., and Dowell, F. E. 2011. Effects of integrating cultivar resistance and fungicide application on Fusarium head blight and deoxynivalenol in winter wheat. Plant Dis. 95:554-560.

48. Willocquet, L., Aubertot, J. N., Lebard, S., Robert, C., Lannou, C., and Savary, S. 2008. Simulating multiple pest damage in varying winter wheat production situations. Field Crop Res. 107:12-28.

49. Willyerd, K. T., Li, C., Madden, L. V., Bradley, C. A., Bergstrom, G. C., Sweets, L. E., McMullen, M., Ransom, J. K., Grybauskas, A., Osborne, L., Wegulo, S. N., Hershman, D. E., Wise, K., Bockus, W. W., Groth, D., Dill-Macky, R., Milus, E., Esker, P. D., Waxman, K. D., Adee, E. A., Ebelhar, S. E., Young, B. G., and Paul, P. A. 2012. Efficacy and stability of integrating fungicide and cultivar resistance to manage Fusarium head blight and deoxynivalenol in wheat. Plant Dis. 96:957-967.

50. Windels, C. E. 2000. Economic and social impacts of Fusarium head blight: Changing farms and rural communities in the Northern Great Plains. Phytopathology 90:17-21.

51. Wong, L. S. L., Abramson, D., Tekauz, A., Leisle, D., and McKenzie, R. I. H. 1995. Pathogenicity and mycotoxin production of Fusarium species causing head blight in wheat cultivars varying in resistance. Can. J. Plant Sci. 75:261-267. 